Supplement of Hydrol. Earth Syst. Sci., 21, 281-294, 2017

http://www.hydrol-earth-syst-sci.net/21/281/2017/

doi:10.5194/hess-21-281-2017-supplement

(C) Author(s) 2017. CC Attribution 3.0 License.

(c) (1)

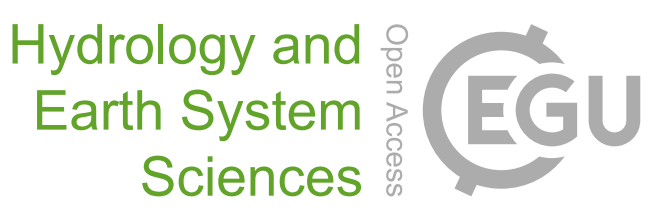

Supplement of

\title{
On the non-stationarity of hydrological response in anthropogenically unaffected catchments: an Australian perspective
}

Hoori Ajami et al.

Correspondence to: Hoori Ajami (hoori.ajami@ucr.edu)

The copyright of individual parts of the supplement might differ from the CC-BY 3.0 licence. 


\section{Introduction}

The supplementary material includes three sections. Section 1 describes the methodology for detecting changes in precipitation seasonality based on the seasonality index and precipitation percentiles between 1984-1996 and 1997-2009 sub-periods. Section 2 describes properties of two remotely sensed vegetation products for exploring annual precipitation-productivity relationships.

Figure S1 shows distribution of water- and energy- limited catchments according to the Budyko framework. In Figure S2 normalized sensitivities of fractional vegetation cover to precipitation for two sub-periods (1984-1996 and 1997-2009) are presented.

Table S1 has the percentages of tree and grass land cover types in catchments with nonstationary hydrologic response. Table S2 and S3 have the results of precipitation seasonality and Spearman rank correlations for catchment classification respectively. Table S4 has the properties of remotely sensed vegetation products. 


\section{Changes in precipitation seasonality}

To detect changes in the precipitation seasonality between the two sub-periods (19841996 and 1997-2009), the bootstrapping approach of Pryor and Schoof (2008) is implemented. It should be noted that the 1997-2009 period corresponds to the millennium drought in Australia (Chiew et al., 2014). For every catchment, 1000 realizations of the mean seasonality index (SI) values during 1997-2009 were generated and 99\% confidence intervals are calculated from the samples. Next, the mean SI values of the 1984-1996 period are compared against the sampling confidence interval to determine the significance of changes in the SI values between the two sub-periods. Results indicate that there has not been a significant intensification of precipitation seasonality across the catchments with non-stationary hydrologic response except for two catchments in group A1 (Table S2). To detect a shift in the timing of precipitation between the two subperiods, the bootstrapping approach is implemented across the precipitation percentiles of catchments with non-stationary hydrologic response. Results indicate that all catchments present significant shifts in timing of the percentile day of the year where the total annual precipitations are reached except in catchments 318076 and G8110004. These shifts are particularly evident for the $25^{\text {th }}$ and $10^{\text {th }}$ percentiles among the catchments with nonstationary hydrologic response (Table S2). 


\section{Remotely sensed vegetation products}

Two additional remote sensing vegetation products, Enhanced vegetation index (EVI) (Huete et al., 2002, 2006), and Vegetation Optical Depth (VOD) (Liu et al., 2011), are used to assess annual precipitation-productivity relationships at the catchment scale. The Australia coverage of despiked EVI dataset (2001-2010) from the Moderate Resolution Imaging Spectroradiometer (MODIS) MOD13Q1 product are obtained from Geoscience Australia. The EVI 16 day product has a spatial resolution of $250 \mathrm{~m}$ and is more sensitive to net primary productivity compared to normalized difference vegetation index (NDVI) (Huete et al., 2002, 2006).

Global long-term VOD dataset (1988-2010) from passive microwave satellites with $0.25^{\circ}$ spatial resolution are obtained from Liu et al. (2011). VOD is related to water content of leaf and woody components of aboveground biomass (Liu et al., 2015). Compared to NDVI, VOD is able to detect structural differences in areas with near-closed canopy.

Because MODIS EVI is only available for smaller time period than the AVHRR $F_{\text {tot }}$ dataset, only Spearman rank correlations between MODIS EVI and fractional vegetation cover is established for individual catchments. Results indicate significant correlations in most catchments (Table S4). For the VOD, correlations with annual precipitation and $\mathrm{F}_{\text {tot }}$ dataset are explored. As shown in Table S4, VOD dataset provide a similar grouping of catchments with non-stationary hydrologic response except for one catchment in class A1 and three catchments in group (B). In these three catchments in group (B), correlation coefficient between annual precipitation and VOD is quite small. 


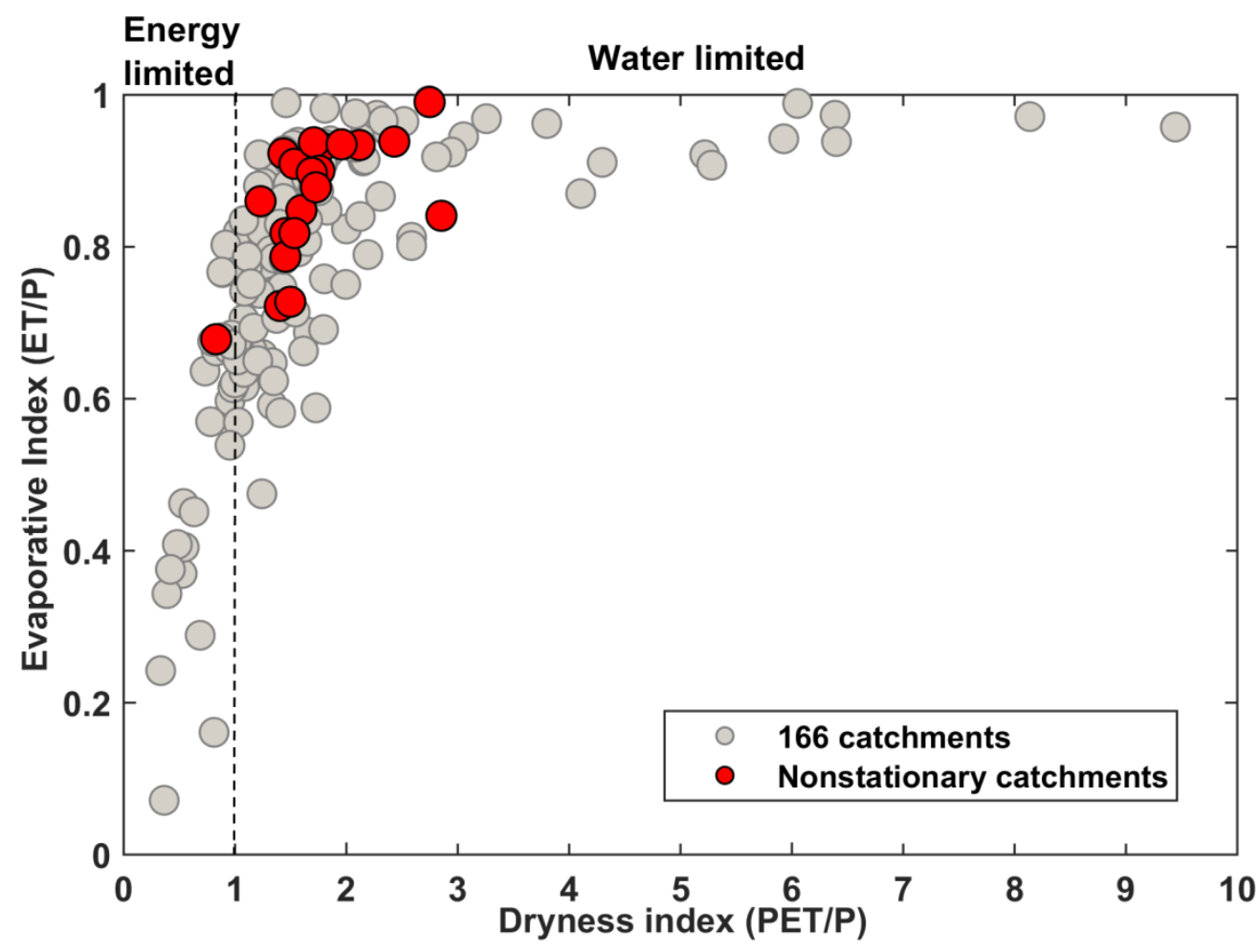

Figure S1: Distribution of water- and energy- limited catchments according to the Budyko framework using data from 166 Hydrologic Reference Stations (HRS) across Australia (1984-2010). Red circles show catchments with non-stationary hydrologic response. The North Esk catchment (318076) in Tasmania is the only energy-limited catchment with non-stationary hydrologic response. 

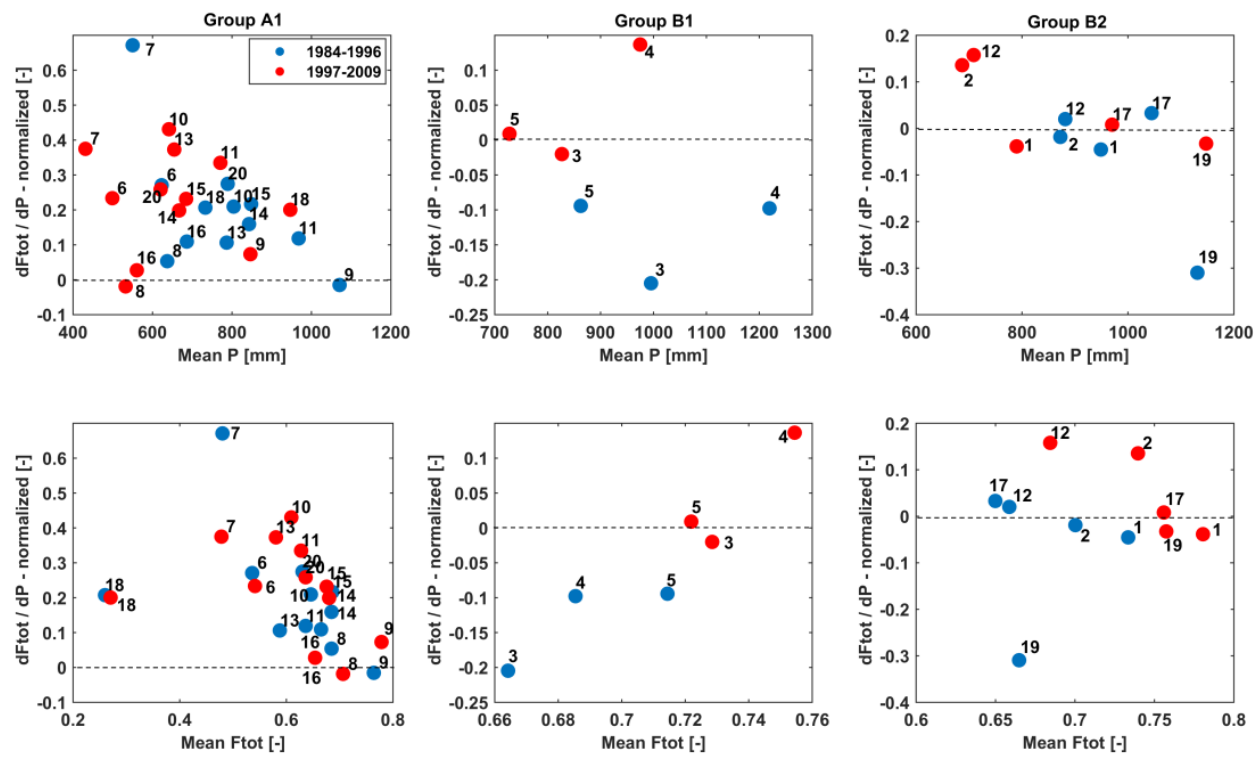

Figure S2: Normalized sensitivities of annual fractional vegetation cover $\left(\mathrm{F}_{\mathrm{tot}}\right)$ to annual precipitation $(\mathrm{P})$ in relation to mean annual precipitation (top) and mean annual fractional vegetation cover (bottom) across three classes of catchments with non-stationary hydrologic response for two sub-periods: 1984-1996 and 1997-2009. For catchment identification numbers refer to Table 1 .

As can be seen in Figure S2, changes in the magnitudes and directions of normalized sensitivities of $\mathrm{B} 1$ and $\mathrm{B} 2$ catchments correspond to increases in fractional vegetation cover during the drier period (1997-2009). Perhaps increases in nutrient availability are the cause of the vegetation increase. In class A1 catchments, changes in the direction of slopes are only observed in catchments 8 and 9 . In catchment 9, the largest difference in mean annual precipitation between the two sub-periods is observed $(224 \mathrm{~mm})$ which is the likely cause of the observed trend. Similar patterns are observed in catchments 12 and 17. Catchment 12 has the smallest fractional vegetation cover in the B2 class (Table 1) and the fractional vegetation cover sensitivity to precipitation is increased in 1997-2009 period due to $173 \mathrm{~mm}$ decline in precipitation. Catchment 17 has the largest difference in fractional vegetation cover between the two sub-periods $(0.11)$ which decreases $F_{\text {tot }}$ sensitivity to precipitation. 
Table S1: Catchments with non-stationary hydrologic response in Australia. Percentages of grass and tree in each catchment are obtained from the National Dynamic Land Cover (NDLC) data set of Australia (Lymburner et al., 2010). Class refers to catchment classification framework presented in Figure 6.

\begin{tabular}{|c|c|c|c|c|}
\hline \multirow{3}{*}{ Station } & \multirow{3}{*}{ Catchment Name } & \multicolumn{2}{|c|}{ NDLC } & \multirow{3}{*}{ Class } \\
\hline & & & & \\
\hline & & $\%$ Grass & \% Tree & \\
\hline 406214 & Axe Creek at Longlea, VIC & 29.1 & 70.9 & A1 \\
\hline 408200 & Avoca River at Coonooer, VIC & 52.8 & 47.2 & A1 \\
\hline 408202 & Avoca River at Amphitheatre, VIC & 47.8 & 52.2 & A1 \\
\hline 410061 & Adelong Creek at Batlow Road, NSW & 31.1 & 68.9 & A1 \\
\hline 410705 & Molonglo River at Burbong, ACT NSW & 17.1 & 82.9 & A1 \\
\hline 410731 & Gudgenby River at Tennent, ACT & 4.8 & 95.2 & A1 \\
\hline & Murrumbidgee River below Lobbs Hole & & & \\
\hline 410761 & Creek, ACT/NSW & 11.9 & 88.1 & A1 \\
\hline & Abercrombie River at Abercrombie, & & & \\
\hline 412028 & NSW & 30.7 & 69.3 & A1 \\
\hline 412066 & Abercrombie River at Hadley No.2, NSW & 35.0 & 65.0 & A1 \\
\hline 415207 & Wimmera River at Eversley, VIC & 33.3 & 66.7 & A1 \\
\hline & East Baines River at Victoria Highway, & & & \\
\hline G8110004 & NT & 3.1 & 96.9 & A1 \\
\hline 405238 & Mollison Creek at Pyalong, VIC & 60.2 & 39.8 & A1 \\
\hline 215004 & Corang River at Hockeys, NSW & 1.0 & 99.0 & B1 \\
\hline 216004 & Currambene Creek at Falls Creek, NSW & 1.0 & 99.0 & B1 \\
\hline 218001 & Tuross River at Tuross Vale, NSW & 2.6 & 97.4 & B1 \\
\hline 212260 & Kowmung River at Cedar Ford, NSW & 7.6 & 92.4 & B2 \\
\hline 215002 & Shoalhaven River at Warri, NSW & 27.1 & 72.9 & B2 \\
\hline 410734 & Queanbeyan River at Tinderry, ACT & 15.6 & 84.4 & B2 \\
\hline 613146 & Clarke Brook at Hillview Farm, WA & 11.3 & 88.7 & B2 \\
\hline 318076 & North Esk, TAS & 9.8 & 90.2 & B2 \\
\hline
\end{tabular}


Table S2: Mean precipitation seasonality index of each catchment with non-stationary hydrologic response for the 1984-2010, 19841996 and 1997-2009 periods. Mean differences in the day of a year where $10^{\text {th }}, 25^{\text {th }}, 50^{\text {th }}, 75^{\text {th }}$ and $90^{\text {th }}$ percentiles of the annual precipitation are reached between the two sub-periods (1984-1996 and 1997-2009). Positive values indicate later onset of the percentile values relative to the 1997-2009 period.

\begin{tabular}{|c|c|c|c|c|c|c|c|c|}
\hline \multirow[t]{2}{*}{ Station } & \multirow{2}{*}{$\begin{array}{c}\text { SI } \\
(1984-2010)\end{array}$} & \multirow{2}{*}{$\begin{array}{c}\text { Mean SI } \\
(1984-1996)\end{array}$} & \multirow{2}{*}{$\begin{array}{c}\text { Mean SI } \\
(1997-2009)\end{array}$} & \multicolumn{5}{|c|}{ Mean differences in the day of a year between the decades } \\
\hline & & & & 10th & 25th & $50^{\text {th }}$ & 75th & 90th \\
\hline 212260 & 0.49 & 0.49 & 0.49 & $27^{*}$ & 13 & $103^{*}$ & -2 & 13 \\
\hline 215002 & 0.57 & 0.57 & 0.56 & $21^{*}$ & $-55^{*}$ & 14 & 39 & 39 \\
\hline 410734 & 0.55 & 0.56 & 0.53 & -2 & -13 & -37 & $108^{*}$ & 34 \\
\hline 613146 & 0.77 & 0.75 & 0.79 & 3 & $11^{*}$ & $-37^{*}$ & 11 & -27 \\
\hline 318076 & 0.47 & 0.45 & 0.5 & 13 & -8 & 28 & -9 & 5 \\
\hline 215004 & 0.57 & 0.57 & 0.57 & 1 & $-35^{*}$ & $85^{*}$ & 29 & -9 \\
\hline 216004 & 0.58 & 0.6 & 0.56 & 7 & 8 & -62 & $83^{*}$ & -57 \\
\hline 218001 & 0.61 & 0.61 & 0.59 & $8^{*}$ & $18^{*}$ & 1 & 64 & 64 \\
\hline 406214 & 0.54 & 0.58 & $0.51^{*}$ & 2 & 11 & -24 & $-4^{*}$ & -26 \\
\hline 408200 & 0.55 & 0.6 & $0.52^{*}$ & $10 *$ & $54^{*}$ & -7 & 25 & 0 \\
\hline 408202 & 0.50 & 0.52 & 0.49 & 4 & $50^{*}$ & -40 & 42 & -49 \\
\hline 410061 & 0.52 & 0.53 & 0.52 & 3 & $21^{*}$ & -20 & -34 & -28 \\
\hline 410705 & 0.53 & 0.54 & 0.53 & 6 & $14^{*}$ & 19 & 8 & 82 \\
\hline 410731 & 0.49 & 0.5 & 0.49 & $11^{*}$ & $98^{*}$ & -11 & -11 & 41 \\
\hline 410761 & 0.49 & 0.49 & 0.47 & 46 & -7 & 29 & 60 & 1 \\
\hline 412028 & 0.46 & 0.46 & 0.45 & $52^{*}$ & $-77^{*}$ & 15 & $65^{*}$ & 53 \\
\hline 412066 & 0.46 & 0.46 & 0.46 & $47^{*}$ & -5 & -17 & 16 & -4 \\
\hline 415207 & 0.51 & 0.53 & 0.49 & 4 & $65^{*}$ & -27 & 4 & 0 \\
\hline G8110004 & 1.1 & 1.08 & 1.12 & -1 & 0 & -2 & -8 & -57 \\
\hline 405238 & 0.53 & 0.56 & 0.51 & $5^{*}$ & $39^{*}$ & -71 & 7 & -47 \\
\hline
\end{tabular}

*The difference in mean SI or the percentile values of the two sub-periods is significant at $\alpha=0.01$. 
Table S3: Spearman rank correlations between annual precipitation and mean annual temperature $\left(\mathrm{r}_{1}\right)$, and fractional vegetation cover with mean annual temperature $\left(\mathrm{r}_{2}\right)$, and mean annual sunshine hours ${ }^{1}\left(\mathrm{r}_{3}\right)$ for catchments with non-stationary hydrologic response in Australia (1984-2010). Class categories refer to the catchment classification framework of Figure 6.

\begin{tabular}{ccccc}
\hline Station & $\mathbf{r}_{1}$ & $\mathbf{r}_{2}$ & $\mathbf{r}_{3}$ & Class \\
\hline 406214 & -0.32 & -0.16 & -0.09 & $\mathrm{~A} 1$ \\
408200 & -0.28 & -0.19 & -0.26 & $\mathrm{~A} 1$ \\
408202 & -0.30 & -0.14 & -0.21 & $\mathrm{~A} 1$ \\
410061 & $-0.58^{*}$ & -0.10 & 0.18 & $\mathrm{~A} 1$ \\
410705 & -0.18 & -0.26 & $-0.46^{*}$ & $\mathrm{~A} 1$ \\
410731 & -0.24 & -0.14 & -0.13 & $\mathrm{~A} 1$ \\
410761 & -0.06 & -0.02 & -0.19 & $\mathrm{~A} 1$ \\
412028 & $-0.53^{*}$ & -0.25 & $-0.47^{*}$ & $\mathrm{~A} 1$ \\
412066 & $-0.43^{*}$ & -0.24 & $-0.52^{*}$ & $\mathrm{~A} 1$ \\
415207 & -0.33 & -0.31 & -0.31 & $\mathrm{~A} 1$ \\
$\mathrm{G} 8110004$ & $-0.54^{*}$ & $-0.57^{*}$ & -0.09 & $\mathrm{~A} 1$ \\
405238 & -0.20 & -0.08 & -0.10 & $\mathrm{~A} 1$ \\
& & & & \\
215004 & 0.03 & 0.11 & $0.50^{*}$ & $\mathrm{~B} 1$ \\
216004 & -0.10 & 0.13 & -0.21 & $\mathrm{~B} 1$ \\
218001 & 0.15 & 0.00 & 0.14 & $\mathrm{~B} 1$ \\
& & & & \\
212260 & -0.32 & 0.19 & -0.13 & $\mathrm{~B} 2$ \\
215002 & -0.09 & 0.01 & 0.04 & $\mathrm{~B} 2$ \\
410734 & -0.06 & -0.06 & -0.01 & $\mathrm{~B} 2$ \\
613146 & -0.01 & 0.16 & 0.08 & $\mathrm{~B} 2$ \\
318076 & 0.18 & 0.14 & 0.07 & $\mathrm{~B} 2$ \\
\hline
\end{tabular}

*Correlation is significant $(p<0.05)$

${ }^{1}$ Sunshine hour data are obtained from seven meteorological stations that are closest to the catchments with non-stationary hydrologic response and have the most number of data records for duration of the analysis (1984-2010). 
Table S4: Spearman rank correlations between annual VOD and annual fractional cover $\left(\mathrm{F}_{\text {tot }}\right)$ from AVHRR $\left(\mathrm{r}_{1}\right)$, annual VOD and annual precipitation $\left(\mathrm{r}_{2}\right)$, and annual EVI and $\mathrm{F}_{\text {tot }}\left(\mathrm{r}_{3}\right)$, in catchments with non-stationary hydrologic response.

\begin{tabular}{ccccc} 
Station & $\begin{array}{c}\mathbf{r} 1 \\
(\mathbf{1 9 8 8 - 2 0 1 0})\end{array}$ & $\begin{array}{c}\mathbf{r} 2 \\
\mathbf{( 1 9 8 8 - 2 0 1 0})\end{array}$ & $\begin{array}{c}\text { r3 } \\
(\mathbf{2 0 0 1 - 2 0 1 0})\end{array}$ & Class \\
\hline 406214 & $0.44^{*}$ & $0.48^{*}$ & $0.72^{*}$ & $\mathrm{~A} 1$ \\
408200 & 0.36 & $0.50^{*}$ & $0.94^{*}$ & $\mathrm{~A} 1$ \\
408202 & $0.63^{*}$ & $0.50^{*}$ & 0.21 & $\mathrm{~A} 1$ \\
410061 & $0.62^{*}$ & 0.08 & $0.79^{*}$ & $\mathrm{~A} 1$ \\
410705 & $0.63^{*}$ & 0.30 & $0.95^{*}$ & $\mathrm{~A} 1$ \\
410731 & $0.82^{*}$ & 0.28 & $0.98^{*}$ & $\mathrm{~A} 1$ \\
410761 & $0.69^{*}$ & 0.17 & $0.95^{*}$ & $\mathrm{~A} 1$ \\
412028 & $0.46^{*}$ & 0.07 & $0.85^{*}$ & $\mathrm{~A} 1$ \\
412066 & 0.36 & -0.12 & $0.84^{*}$ & $\mathrm{~A} 1$ \\
415207 & $0.58^{*}$ & $0.48^{*}$ & 0.60 & $\mathrm{~A} 1$ \\
$\mathrm{G} 8110004$ & 0.40 & $0.66^{*}$ & 0.27 & $\mathrm{~A} 1$ \\
405238 & $0.53^{*}$ & 0.38 & $0.89^{*}$ & $\mathrm{~A} 1$ \\
& & & & \\
215004 & $0.47^{*}$ & -0.02 & 0.44 & $\mathrm{~B} 1$ \\
216004 & $0.63^{*}$ & -0.42 & $0.82^{*}$ & $\mathrm{~B} 1$ \\
218001 & 0.41 & -0.04 & $0.82^{*}$ & $\mathrm{~B} 1$ \\
& & & & \\
212260 & 0.20 & 0.06 & 0.62 & $\mathrm{~B} 2$ \\
215002 & $0.49^{*}$ & -0.19 & $0.92^{*}$ & $\mathrm{~B} 2$ \\
410734 & $0.54^{*}$ & 0.15 & $0.73^{*}$ & $\mathrm{~B} 2$ \\
613146 & $0.54^{*}$ & $-0.43^{*}$ & 0.38 & $\mathrm{~B} 2$ \\
318076 & $0.65^{*}$ & -0.01 & 0.61 & $\mathrm{~B} 2$ \\
\hline
\end{tabular}

*Correlation is significant $(p<0.05)$ 